\title{
UMNO OnLINE dan Fungsinya dalam Penerbitan Berita Politik dalam TALIAN di MaLAYSIA
}

\author{
Rofikah Ahmad \\ Universiti Malaya \\ rofikah707@yahoo.com
}

Abdullah al-Hadi Hamdan

Universiti Malaya

hadihamdan.um@gmail.com

Mohamad Saleeh Rahamad

Universiti Malaya

saleeh@um.edu.my

\section{UMNO ONLINE AND ITS FUNCTION IN ONLINE POLITICAL NEWS PUBLICATION IN MALAYSIA}

\begin{abstract}
This article is about online publishing in a political party like UMNO by looking at its functions applied in the field of communication. This political party applies the development of online publishing by using UMNO Online as the party's official website. This study focuses specifically on the function of the UMNO Online created in online political news publishing in Malaysia and the UMNO Online factor established as well as how the development of online political publishing to reflect the background of the study. The function of UMNO Online is based on the scope of the study, namely the content published in June 2011 will be examined based on the role of UMNO Online in addressing these issues through ethical news writing, with an emphasis on the pattern of news published. In addition, the evolution of communication has influenced UMNO, which has also changed with the existence of websites in the association as a new platform for the party, based on the latest developments that also require the use of technology. The development of UMNO Online which started from a special unit and through various changes that eventually became a news portal that is interactive in nature by combining all media. The results of the research found that current developments motivate UMNO as a political party that holds some of the leadership role in the country's administration also undergoes transformation using cyber media. Through the study, it can be concluded that UMNO Online plays a news role in rejecting the allegations made by the opposition party.
\end{abstract}

Keywords: UMNO, political news, Malaysia, online news, Hindraf, Najib Razak 


\section{PENGENALAN}

Internet telah mengubah senario komunikasi termasuk bagaimana kerjanya berfungsi, berkongsi sebarang maklumat dan kesannya yang mempengaruhi khalayak. Kemampuan Internet dalam mengubah landskap media dan komunikasi di negara ini turut mempengaruhi corak penulisan berita. Keadaan ini secara tidak langsung telah mewujudkan suatu gaya baharu dalam penghasilan berita iaitu secara dalam talian. Kewartawanan dalam talian memberi implikasi besar dalam membentuk kembali cara pemikiran, pandangan, kepercayaan, dan persepsi masyarakat terhadap suatu prosedur dan kebiasaannya. Bukan hanya menjadi alat yang terkenal bagi komunikasi politik, tetapi juga menjadi forum penting untuk perubahan pola pemikiran sivik, mobilisasi suatu masyarakat, perjuangan politik, dan reformasi politik.

Di Malaysia, penerbitan berita melalui Internet adalah antara berita popular dalam kalangan masyarakat (Sani, 2010). Terdapat dua faktor utama yang menyebabkan penerbit akhbar cetak mula melihat Internet sebagai satu peluang baru, iaitu kos yang lebih rendah dan tabiat membaca yang telah berubah kepada bacaan di Internet sama ada menerusi komputer mahupun telefon bimbit (Dozier \& Rice, 1984). Meskipun akhbar seperti Utusan Malaysia, The Star, Berita Harian dan News Straits Times mendominasi dalam penerbitan berita politik, kemunculan Internet telah mewujudkan banyak alternatif dalam cara mendapatkan berita dan maklumat politik tanah air dengan lebih cepat dan murah (Gomez \& Jomo, 1999). Dari segi fungsi Internet dalam mendapatkan maklumat dan berita semasa, kajian yang telah dilakukan oleh Adnan Hussein dan Kamaliah Hj Siarap (2000) mendapati bahawa penggunaan Internet untuk tujuan ini adalah tinggi. Kewujudan portal berita dalam talian memungkinkan penerbitan secara dalam talian dengan penggunaan secara menyeluruh terhadap ruang yang ada untuk memaparkan suatu penyampai mesej khususnya.

Penggunaan Internet dilihat sebagai kemudahan baru bagi penerokaan bidang teknologi yang mampu bersaing dengan berita elektronik. Internet berperanan dalam memperkenalkan, memupuk, dan mengembangkan idea-idea falsafah demokrasi, sementara pihak yang lain menimbulkan keraguan (Rice, 2002). Ini memberi peluang kepada organisasi, usahawan, pihak individu malah parti politik yang seterusnya berkembang menjadi suatu kewibawaan kepada seluruh dunia untuk menggunakan kelebihan Internet . Begitu juga di Malaysia misalnya, dengan kewujudan portal berita dalam talian yang termasuklah Pertubuhan Kebangsaan Melayu Bersatu atau UMNO yang bertunjangkan kepentingan organisasi sebagai suatu sumber maklumat kepada masyarakat. Portal berita dalam talian rasmi UMNO iaitu UMNO-Online pada asalnya muncul sekitar tahun 1999 dengan nama e-UMNO sebagai langkah membantu kerajaan dalam menggunakan Internet untuk memerangi diayah, fitnah serta tohmahan pihak tertentu yang disebar melalui jaringan maklumat tersebut. E-UMNO juga berfungsi menjawab segera tohmahan serta menjelaskan kedudukan sebenar sesuatu perkara yang diputarbelitkan pembangkang. Portal ini juga dianggap sebagai gerbang Internet kepada UMNO yang bersifat interaktif dengan rakyat dan membolehkan pemimpin parti berinteraksi secara dalam talian termasuk menerusi persidangan atau mel elektronik (e-mel).

Menurut McQuail (1987), media pembangunan menawarkan banyak prinsip yang bersesuaian untuk menentukan dan mencerminkan kaedah atau kerangka akhbar yang diamalkan dengan fokus pada masalah ekonomi, keperluan untuk pembangunan masyarakat, aspek budaya dan bahasa kebangsaan. Laporan yang dianggap berharga dan membantu pencapaian kerajaan dapat mempengaruhi sokongan masyarakat di sebalik perkembangan 
dasar pemerintah. Oleh itu, jika sesuatu isu itu berkaitan dengan perbincangan utama sama ada menyokong pihak pemerintahan atau tidak, berita seharusnya mencerminkan kecenderungan yang dinyatakan baik, negatif, atau seimbang. Ini kerana kemajuan yang dimaksudkan berkaitan dengan rancangan dan tindakan pemerintah.

Kewartawanan dalam talian pada tahun 1998 dan tahun-tahun berikutnya, telah berubah menjadi bukan sahaja sebagai saluran protes politik, tetapi juga pengaruh utama untuk perubahan dan pembaharuan demokratik (Abbott, 2004). Dalam beberapa tahun yang lepas, perubahan sikap masyarakat terhadap mekanisme kekuasaan dan harapan hegemoni telah memicu gerakan masyarakat dan demonstrasi anti-pemerintah di Malaysia, seperti di banyak negara membangun lain, mobilisasi politik dan telah menimbulkan konflik politik atau pergolakan, dalam konteks Malaysia secara signifikan. Fenomena baharu dalam politik Malaysia khususnya selepas Datuk Seri Anwar Ibrahim dipecat daripada jawatan Timbalan Perdana Menteri pada tahun 1998 telah mendorong rakyat menentang kerajaan yang didukungi oleh UMNO sebagai parti terbesar dalam kerajaan. Antaranya termasuklah berita yang mendesak Perdana Menteri pada tahun tersebut, Datuk Seri Dr Mahathir Mohamad untuk meletakkan jawatannya. Seterusnya demonstrasi dan rusuhan di jalan raya utama dalam Bandaraya Kuala Lumpur, bantahan terhadap kerajaan dan parti pemerintah turut disuarakan melalui pelbagai laman web seperti Reformasi dan Malaysiakini yang umumnya menumpukan kepada isu tadbir urus, keadilan, ketelusan dan agihan kekayaan secara adil (Mohd Yusof \& Azlan, 2002).

Walaupun revolusi kuasa awam Malaysia (Bersih 2 atau yang disebut T-shirt Kuning) pada tahun 2011 selalu damai dan berwarna-warni, tetapi tetap mempunyai tujuan bantahan terhadap kerajaan dan untuk menjatuhkan parti pemerintah, Barisan Nasional (BN) yang memerintah negara selama beberapa dekad sejak Kemerdekaan Malaysia pada tahun 1957, dan mengubah sistem politik. Berikutan stereotaip negatif dan tindakan manipulatif berkaitan kerajaan dan UMNO sebagai parti komponen terbesar secara berterusan dalam Barisan Nasional, kepimpinan tertinggi parti mewujudkan media alternatif bagi mengimbangi dan menangkis tuduhan palsu serta memberi penerangan kepada masyarakat. Selepas penstrukturan semula pada tahun 2000, e-UMNO telah dikenali sebagai UMNO Online.

Penyelidikan ini difokuskan pada fungsi dan amalan etika kewartawanan ini penting bagi memastikan had yang telah digariskan dalam bentuk penulisan kewartawanan dipatuhi dan menjadi sebahagian daripada jati diri wartawan yang berwibawa dan dihormati oleh khalayak pembaca. Sejak beberapa tahun kebelakangan ini, anggapan bahawa mobilisasi dan konfrontasi politik telah meningkat dan mendalam di Malaysia kerana lebih banyak orang telah mengubah pandangan mereka terhadap rejim dan norma hegemoni akibat kesan teknologi komunikasi baru, terutama kewartawanan bebas atau alternatif media dalam talian. Ramai yang juga membaca laman berita web alternatif cenderung menjadi pesimis dan menentang pemerintahan dan norma-norma masa kini. Tentunya media baru diketengahkan sebagai saluran utama parti dalam menyampaikan maklumat serta menjawab isu-isu berbangkit sedangkan dalam masa yang sama UMNO perlu berdepan dengan cabaran media baru parti politik lain seperti Harakah (www.harakahdaily.my), DAP Malaysia (www.dapmalaysia.org), Keadilan Rakyat (www.keadilanrakyat.org) dan juga portal-portal berita Internet yang bebas dan tidak terikat dengan kawalan permit penerbitan. Perubahan pemikiran masyarakat adalah faktor teras yang mendorong mobilisasi politik terhadap mekanisme kekuatan dan norma konvensional. Warganegara tidak akan pergi ke jalanan, mengorbankan nyawa atau masa mereka dan menentang pihak berkuasa untuk 
menjatuhkan pemimpin atau rejim kecuali pemikiran mereka telah sepenuhnya berubah ke arah yang terakhir ini. Kewartawanan dalam talian, terutama secara dalam talian yang bebas mengangkat dan mempertajam kekacauan dan konflik politik sambil mengubah pemikiran masyarakat (pemikiran, kepercayaan, dan persepsi) terhadap rejim hegemoni dan konstitusi konvensional.

Berdasarkan kriteria teori tersebut, tujuan artikel ini adalah secara umum untuk lebih meneroka kepada peranan kewartawanan dalam talian, UMNO Online yang berfungsi sebagai wadah utama dalam menyampaikan berita-berita politik dan dasar parti kepada masyarakat umum. Untuk memenuhi objektif penyelidikan ini, kajian ini akan meneroka sejauh mana UMNO Online mampu mengubah pemikiran masyarakat melalui prinsip utama dalam etika kewartawanan itu sendiri. Walaupun penyelidikan ini telah dilakukan dalam konteks Malaysia, hasil dan penemuan dapat diterapkan pada negara lain yang mengadaptasi penerbitan dalam talian.

\section{ULASAN KAJIAN LEPAS}

Beberapa penyelidikan terhadap penerbitan dalam talian telah dilakukan khususnya terhadap portal akhbar yang semakin meluas digunakan. Antaranya Nolan Jeffrey (2004) yang menghuraikan konsep teknologi maklumat dan perkembangannya di Malaysia selain menghuraikan ciri-ciri fizikal dan teknikal yang terdapat dalam penerbitan dalam talian. Beliau turut meneliti potensi akhbar elektronik dalam menghadapi persaingan dengan penerbitan bercetak. Selain itu, Kuan Yee Cheng (1999) mengkaji trend penerbitan elektronik terhadap institusi akhbar tempatan seperti The Star, tetapi kajiannya bertumpu pada aspek teknikal serta proses penggunaan teknologi dalam bidang penerbitan. Backer (2010) pula meneliti perkembangan akhbar Internet di Malaysia dengan menilai perkembangan Utusan Malaysia dari segi organisasinya, sambutan dan pendapatan iklan untuk akhbar tersebut. Selain itu, kajian tersebut juga telah mendapatkan persepsi khalayak berkaitan perkembangan akhbar Internet, iaitu Utusan Online. Perkembangan mengenai penerbitan elektronik dalam mempengaruhi struktur organisasi agensi akhbar seperti The Star dan Harakah (Maizatul Nazlina, 2002).

Penerbitan dalam talian merupakan penerbitan yang popular dalam kalangan parti politik tempatan di negara ini. Keadaan ini berlaku lantaran medium seperti akhbar yang mampu menentukan sambutan dan sokongan terhadap parti politik yang tertentu (Abdul Nassir, 2003; Che Yazid, 2001; Ahmad Zaky, 2002). Selain akhbar, terdapat juga kajian yang tertumpu pada syarikat penerbitan buku yang secara tidak langsung menerima tempias daripada populariti penerbitan dalam talian (Yen, 2008). Penerbitan buku yang biasanya mengkhusus pada material bercetak terpaksa mendepani cabaran sengit daripada populariti buku elektronik yang kebanyakannya boleh dibaca secara percuma menerusi laman web.

Terdapat juga kajian yang berfokus pada pelanggaran etika dalam penerbitan berita dalam talian. Misalnya, Che Yazid (2001) memfokuskan kepada pelanggaran etika kewartawanan di Malaysia dengan mengkhusus kepada akhbar Utusan Malaysia yang melibatkan kepada dua isu, iaitu liputan berita dalam pemilihan kepimpinan Gabungan Persatuan Penulis Nasional (GAPENA) dan liputan berita terhadap politik Abdul Rahim Thamby Chik yang didakwa mempunyai hubungan sulit dengan gadis bawah umur. Namun, tumpuan yang diberikan berkisar kepada pendekatan sejarah dan komunikasi yang hasilnya mendapati wujud bentuk pemberitaan yang tidak seimbang, sekali gus melanggar etika kewartawanan. Dalam pada 
itu, Ghani (2005) mendapati bahawa berita talian telah memudahkan masyarakat mengetahui perkembangan berita semasa melalui aplikasi komputer dan teknologi baharu seperti Internet . Konsep-konsep baru yang mendapat perhatian masyarakat seperti globalisasi dan dunia tanpa sempadan turut membuka jalan yang amat luas kepada penerbitan berita secara dalam talian. Selain itu, kajian ini turut menjurus kepada perkembangan berita dalam talian yang semakin mendapat sambutan dan tidak menganalisis fungsi organisasi terbabit yang menggunakan media baru dalam pemberitaan.

Jelaslah bahawa kajian yang dilaksanakan terhadap laman web UMNO Online adalah berbeza dengan kajian terdahulu yang lebih menjurus kepada penerbitan dalam talian dan kesannya kepada masyarakat. Jika terdapat pun yang berkaitan etika dalam kewartawanan, kajian tersebut lebih menjurus kepada akhbar konvensional dan bukannya bahan terbitan secara maya. Ini adalah berbeza dengan kajian yang dibuat kepada UMNO Online sebagaimana objektifnya yang mahu melihat fungsinya sebagai sebuah laman dalam talian kepada pertubuhan siasah yang mendukung kerajaan Barisan Nasional. Biarpun terdapat kajian terhadap akhbar-akhbar pertubuhan siasah yang lain, masih tidak terdapat kajian terhadap fungsi dan amalan etika untuk bahan terbitan yang menjurus pada UMNO.

\section{UMNO Online dan Perkembangan Penerbitan Politik dalam Talian di Malaysia}

Menurut laporan Penyata Tahunan UMNO (1999-2000), sebuah unit khas telah dikendalikan oleh e-UMNO yang terdiri daripada enam orang kakitangan telah diwujudkan. Pada ketika itu, Rosnah Majid telah diberikan tanggungjawab untuk mengetuai unit ini. Selain menjalankan beberapa tugas untuk pilihan raya umum dan propaganda oleh parti pembangkang dan kerajaan, unit ini bertanggungjawab untuk menerbitkan Berita Elektronik UMNO, (e-UMNO). Pada 1 Mac 2000, pelancaran akhbar elektronik UMNO ini dilakukan oleh Presiden Parti, Tun Dr. Mahathir Mohamad yang juga Perdana Menteri Malaysia, di Menara Dato 'Onn, Ibu Pejabat UMNO. Di samping itu, e-UMNO juga memberikan maklumat terkini mengenai UMNO, berita-berita politik dan perkembangan kerajaannya. Unit Khas e-UMNO terdiri daripada enam ahli pasukan yang menguruskan sepenuhnya bahan dan teknikal rangkaian Internet. E-UMNO dikenali sebagai gerbang berita yang membolehkan akses telefon bimbit menggunakan teknologi tanpa wayar (WAP). Tugas barisan pegawai yang berkenaan adalah untuk memeriksa permasalahan harian yang bangkit dalam laman Internet dan seterusnya memberi respons berdasarkan fakta dan hujah yang kukuh, serta memberikan informasi dan maklumat yang relevan dengan bangsa dan negara kepada agenda kerajaan dan UMNO.

Menyedari bahawa Internet boleh dijadikan wahana untuk publisiti, promosi, pemasaran dan penyampaian sesuatu maklumat dengan laman web dibina sebagai hebahan kepada khalayak keseluruhannya, maka pada tahun 2000 penstrukturan semula dilakukan. E-UMNO diletakkan di bawah Bahagian Penerangan Ibu Pejabat UMNO dengan nama baru, iaitu Unit UMNO-online. Bahagian Penerangan tersebut diketuai oleh Setiausaha Bahagian, iaitu Shuhaimi Che Hussin, dengan empat unit lain, iaitu Unit Audio dan Visual, Unit Latihan dan Kursus, dan Unit Penerbitan selain Unit UMNO-online. Unit UMNO-online tersebut kemudiannya diketuai oleh Abdul Shariff Hamid yang turut dianggotai oleh enam orang kakitangan melibatkan wartawan, pereka grafik, jurugambar dan kerani.

Pada tahun 2004, penstrukturan semula Ibu Pejabat UMNO turut memberi kesan kepada Unit UMNO-online apabila ia dipindahkan ke bahagian Perhubungan Awam dan Media. 
Perubahan kepimpinan tertinggi di Ibu Pejabat UMNO membawa kepada penambahbaikan semua bahagian dalam Ibu Pejabat UMNO itu sendiri termasuklah Unit UMNO-online. Namun demikian, tanggungjawab dan tugas yang dilaksanakan masih sama iaitu menulis berita dan rencana mengenai parti atau isu-isu semasa serta membuat liputan mesyuarat pengurusan dan Majlis Tertinggi. Ia juga bertanggungjawab menangkis dan memantau laman web parti lawan, merakam dan memuatkan gambar majlis-majlis rasmi yang berkaitan dengan UMNO (Penyata Tahunan UMNO 2003 - 2004).

Bahagian Perhubungan Awam ini diketuai oleh Hafizah Abu Bakar dengan empat unit di bawahnya iaitu Unit Media, Unit Kaunter Mesra Ahli dan Pengaduan Awam, Unit Galeri dan Perhubungan Luar Negara serta Unit UMNO-online. Perubahan tersebut turut menyaksikan perubahan ketua unitnya apabila Fadzil Abdul Rashid menjadi terajunya. Dalam waktu tersebut, berlaku pengecilan unit apabila kakitangan yang bertugas dalam unit UMNO-online menjadi tiga orang termasuk ketua unit, seorang wartawan dan seorang jurugambar. Sebagai laman rasmi parti, laman ini menerima pelawat yang menjangkau tujuh juta orang setakat 1 Mei 2005, sekali gus menjadikan ia antara laman web politik popular bagi pengguna Internet yang ingin mengetahui latar belakang dan perkembangan semasa parti. Jumlah ini jika dilihat mulai Jun 2004 adalah sangat efektif dengan setiap 1 minit, laman ini menerima 350 pengunjung sehari untuk tempoh kurang 24 jam (Penyata Tahunan UMNO 2004-2005).

Transformasi politik yang dilaksanakan oleh Perdana Menteri merangkap Presiden UMNO, Dato' Seri Mohd Najib Tun Abdul Razak turut melibatkan penstrukturan semula Ibu Pejabat UMNO. Seperti yang dinyatakan oleh Setiausaha Kerja UMNO, Datuk Ab Rauf Yusoh (2011), Penubuhan Bahagian Media yang berkuat kuasa pada 2 Januari 2010 adalah satu perubahan besar pada UMNO Online apabila ia melibatkan pemantapan sebuah bahagian yang baru dan terkini. Bahagian Media melaksanakan tugas media bukan saja meliputi Ibu Pejabat UMNO sebaliknya menjangkau kepada tugasan melibatkan liputan parti di seluruh negara dan juga peringkat antarabangsa dengan asas pemberitaan berlandaskan laman rasmi UMNO Online. Pemberitaan dan paparan dalam talian dibuat seiring dengan perubahan landskap media baru alam siber. Menurut Ahmad Kamal (2011), UMNO Online menjadi platform utama bagi menyampaikan informasi semasa parti termasuklah menangkis manipulasi dan isu-isu yang dilontarkan oleh pihak pembangkang. Agenda Bahagian Media ialah menyokong matlamat parti, iaitu untuk menang Pilihan Raya Umum ke-13 selaras dengan perjuangan sebagai sebuah parti politik yang menyokong gagasan Kebangsaan Melayu demi mempertahankan maruah dan martabat agama, bangsa dan negara. Aspek pemberitaan pula bertumpu pada aktiviti parti, isu-isu semasa dan arahan daripada pihak pengurusan parti.

\section{KAEDAH KAJIAN}

Kajian ini menggunakan kaedah analisis tesktual bertema secara kualitatif (Hsieh \& Shannon, 2005) dan hanya menumpukan perhatian untuk mengenal pasti nilai kandungan serta peranan yang dimainkan oleh UMNO Online. Menerusi analisis tersebut, sejauh mana UMNO Online mampu mengubah pemikiran masyarakat melalui prinsip utama dalam etika kewartawanan akan dibincangkan dalam bentuk isu, tema atau kategori tertentu. Skop kajian ini tertumpu pemaparan berita UMNO Online pada Jun 2011. Ini kerana UMNO sebagai pendukung parti pemerintah ketika itu menghadapi cabaran pergerakan massa sebagai contoh perhimpunan Bersih 2.0. yang pastinya dapat menunjukkan perlunya suatu analisis dilakukan, iaitu melihat bagaimana UMNO menerusi UMNO Online menangani isu-isu tersebut menerusi 
penulisan berita beretika. Selain itu juga, dalam tempoh tersebut UMNO berdepan dengan mesyuarat UMNO di 191 bahagian yang tentunya akan dapat memperlihatkan keperluan kajian, iaitu untuk melihat fungsi UMNO Online sebagai lidah rasmi parti UMNO dalam Barisan Nasional selaku kerajaan Malaysia.

Penyelidik akan menilai dan menghubungkan keseluruhan kandungan yang ditunjukkan dalam UMNO Online dengan objektif utama kajian tersebut dijalankan. Kandungan yang diterbitkan pada bulan Jun akan diteliti berdasarkan peranan yang berkaitan dengan penerbitan UMNO Online, dengan penekanan pada corak berita yang diterbitkan. Berdasarkan objektiviti kewartawanan yang terdapat dalam UMNO Online, pendekatan analisis kandungan digunakan untuk menentukan kepentingan kandungan dan peranan yang dimainkan oleh UMNO Online dalam memberi penerangan tentang langkah membantu kerajaan dan UMNO.

Pada bulan Jun 2011, tugasan kakitangan Bahagian Media tertumpu kepada hal-hal berkaitan parti, para pemimpin tertinggi UMNO dan juga aktiviti semasa termasuklah penglibatan dalam Mesyuarat UMNO Bahagian yang sedang bersidang. Faktor utama dipertimbangkan dalam UMNO Online ialah apa-apa sahaja bahan mestilah ke arah mendorong pembaca membuat keputusan menyokong Barisan Nasional dan memperkukuh agenda perjuangan UMNO. Dalam hal ini juga, petugas media tidak hanya tertumpu kepada skop atau agihan tugas yang diberi sebaliknya turut bersifat kreatif dan inovatif dalam menganalisis isuisu semasa yang boleh menyumbang kepada sokongan terhadap Barisan Nasional. Berdasarkan objektif utama penubuhan berita dalam talian sebagaimana yang disebutkan, iaitu sebagai langkah membantu kerajaan dalam menggunakan Internet untuk memerangi diayah, fitnah serta tohmahan pihak tertentu yang disebar melalui jaringan maklumat tersebut.

\section{DAPATAN KAJIAN DAN PERBINCANGAN}

UMNO Online berperanan sebagai saluran kepada parti politik yang berpihak kepada kerajaan Malaysia. Kerajaan di mana-mana pun, tanpa mengira ideologi menganggap bahan terbitan sebagai instrumen hegemoni yang penting untuk mengekalkan kuasanya. Dalam hal ini, UMNO Online bertindak sebagai wadah bagi parti politik yang mewakili kerajaan dan para pemimpinnya untuk menyalurkan segala dasar, perancangan dan kegiatannya. Melalui pemaparan berita pada tahun 2011, sebanyak 425 artikel diterbitkan dalam bentuk berita, artikel, e-mel dari pembaca dan petikan daripada blog terpilih untuk menangani isu-isu politik ini menerusi penulisan berita beretika. Tujuan UMNO Online adalah untuk memberikan data mengenai tindakan yang diambil oleh kerajaan dan UMNO.

\section{Perhimpunan Bersih 2.0}

Pada 10 November 2007, negara dikejutkan dengan satu tunjuk perasaan oleh sebuah badan bukan kerajaan (NGO) atas nama Gabungan Pilihan Raya Bersih dan Adil (Bersih). Aktiviti yang sama telah dilakukan sekali lagi pada 9 Julai 2011 oleh NGO yang sama atas nama Bersih 2.0. NGO tersebut telah mendapat sokongan daripada pemimpin-pemimpin pembangkang termasuklah ketuanya, yang juga Penasihat Umum PKR, Dato' Seri Anwar Ibrahim; Pengerusi DAP, Karpal Singh dan Setiausaha Agungnya, Lim Guan Eng serta Mursyidul Am PAS, Datuk Nik Abdul Aziz Nik Mat iaitu pemimpin tertinggi PAS dan Tuan Haji Abdul Hadi Awang, Presiden PAS. Lebih dari itu, Dr Syed Azman Syed Ahmad Nawawi, ahli Jawatankuasa PAS Pusat, berjanji untuk mengatur 100,000 peserta dalam perhimpunan tersebut. Menurut Harakah, lapan tuntutan Bersih dalam perhimpunan itu antaranya ialah: 
- Nyahaktifkan senarai pengundian sesuai dengan daftar Jabatan Pendaftaran Negara untuk "pengundi hantu" seperti yang telah mati dan pendaftaran pengundi automatik.

- Untuk mereformasi undi pos, semua pemilih harus layak untuk melakukan pengundian secara pos atau dengan proses pengundian lebih awal jika mereka tidak dapat mengundi pada hari yang relevan dan mesti jelas.

- Bagi mengelakkan seseorang atau pengundi hantu mengundi beberapa kali, dakwat secara kekal digunakan

- Minimum tempoh kempen adalah 21 hari, selebihnya masa bagi calon untuk penyebaran bahan, terutama di kawasan pedalaman dan luar bandar.

- Pendekatan media secara bebas dan saksama, yakni agensi media yang dibiayai oleh pemerintah, juga dapat memberikan perwakilan yang tidak berat sebelah dan adil bagi semua pihak dalam konflik tersebut.

- Memperkukuhkan agensi awam dan pegawai pemerintah secara tidak adil serta mempertahankan undang-undang secara demokratik. Untuk bertindak secara autonomi, serta menegakkan undang-undang dan melindungi hak asasi manusia, institusi awam mesti diperbaharui, - dengan kata lain pilihan raya yang bebas dan saksama, badan kehakiman autonomi dan Polis Diraja Malaysia mesti bertindak secara profesional.

- Elakkan rasuah, kerana rasuah adalah tindakan menipu pengundi untuk kepentingan peribadi, dan pembelian undi dalam pilihan raya juga dapat dihentikan.

- Hentikan politik kotor.

Sebagai sebuah laman rasmi parti yang berpihak kepada kerajaan Malaysia, wartawan UMNO Online melaksanakan tugas sebagaimana terkandung dalam klausa Etika Kewartawanan Malaysia iaitu melaporkan kebenaran dan menghormati hak orang ramai untuk mendapat maklumat yang benar. Untuk melihat klausa tersebut, UMNO Online memaparkan beritaberita yang berkait dengan dasar kerajaan, penerangan parti dan menjawab isu yang dilontarkan pembangkang dan menyampaikan maklumat kepada orang ramai. Berdasarkan isu-isu tersebut, UMNO Online berperanan memberikan penerangan berdasarkan hujah relevan dan bukti kukuh dengan mengadakan wawancara dengan pemimpin tertinggi parti, pemimpin rakyat dan pihak yang mempunyai kepentingan dalam masyarakat. Sepanjang bulan Jun, isu-isu yang timbul sedaya upaya ditangkis melalui berita-berita yang disiarkan dalam UMNO Online khususnya berita utama dan berita eksklusif. Pada masa yang sama, UMNO Online juga turut menggunakan YouTube, iaitu sebuah laman perkongsian video yang boleh dilayari oleh khalayak melalui pautan dalam UMNO Online. YouTube ini digunakan sebagai alternatif kepada pembaca iaitu bukan hanya menatap teks tetapi dalam masa yang sama mampu mendengar wawancara atau temubual berkaitan isu dan program-program semasa dalam UMNO dan kerajaan Barisan Nasional. Penerangan bergambar atau rakaman video sukar disangkal daripada aspek kesahihannya dan ia lebih digemari oleh khalayak.

\section{Dasar Kerajaan}

Praktis dasar kerajaan dilaksanakan oleh kepimpinan parti dengan menyokong melalui tindakan yang dibuat. Ini dapat dilihat dalam berita yang bertajuk, "BN percaya sokongan rakyat menerusi demokrasi, bukan demonstrasi" bertarikh 30 Jun 2011 yang menegaskan 
bahawa kerajaan yang ada mendukung konsep demokrasi berparlimen yang merujuk kepada demokrasi perwakilan, iaitu kerajaan dilantik oleh rakyat yang diwakili wakil Parlimen daripada Dewan Rakyat. Menurut Nik Yahya (2012) demokrasi berparlimen juga disebut sebagai demokrasi berperlembagaan atau kuasa daripada rakyat melalui pilihan raya. Amalan ini diguna dalam pentadbiran Malaysia dan menjadi pegangan kepada Barisan Nasional sebagai sebuah kerajaan. Berita dalam UMNO Online diperkukuh melalui ayat-ayat tersebut bagi menjelaskan berkaitan tugas utama wartawan adalah melaporkan kebenaran:

- Perdana Menteri, Datuk Seri Najib Tun Razak berkata Barisan Nasional (BN) tidak mahu menang pilihan raya secara penipuan tetapi mahu menang atas sokongan dan kepercayaan rakyat kepada BN.

- Katanya keharmonian kaum yang dinikmati oleh rakyat Malaysia terutama di Sabah tidak harus diambil ringan, kerana menurut Perdana Menteri, rancangan seperti mengadakan perhimpunan haram boleh membawa keburukan dengan sekelip mata kepada semua.

- Mengenai Gagasan 1Malaysia, beliau menekankan perlunya mempunyai dasar-dasar dan sistem yang adil di bawah prinsip inklusif untuk semua kaum selain keadilan sosial di negara ini.

\section{Penerangan Parti}

Selaras dengan tugas wartawan dalam menerbitkan fakta dan menilai hak orang ramai untuk memperoleh maklumat yang benar, UMNO Online membuat penerangan berkaitan dasar parti iaitu UMNO yang mempunyai dasar dan matlamat sebagai sebuah parti politik yang berjuang menyokong cita-cita kebangsaan Melayu untuk memartabatkan maruah bangsa, agama dan negara. Dalam hal tersebut, pemimpin UMNO berusaha menerangkan kepada rakyat berkaitan perkembangan semasa dan penggunaan media baru yang berkisar tentang politik semasa tanpa meninggalkan etika kewartawanan, iaitu kebenaran laporan berita dan hak orang ramai untuk memperoleh berita yang tulus. Perkara ini dapat dilihat menerusi berita bertarikh 30 Jun "Perhimpunan Haram Ada Agenda Tersirat", yang melaporkan Naib Presiden UMNO, Dato' Sri Hishammuddin Tun Hussein memberikan penerangan berkaitan perhimpunan Bersih yang telah diputuskan oleh mahkamah sebagai perhimpunan haram. Pada bulan Julai 2005, Bersih ditubuhkan oleh Jawatankuasa Bertindak Bersama Bagi Reformasi Sistem Pilihan Raya, yang mengumpulkan 70 organisasi, termasuk enam parti politik. Organisasi itu yang didakwa sebagai tidak adil dan tidak telus, ditubuhkan untuk menganjurkan reformasi dalam pilihan raya di Malaysia, namun organisasi ini tidak didaftarkan di bawah Akta Pertubuhan 1966. Bersih telah disahkan sebagai sebuah pertubuhan haram yang diumumkan oleh Kementerian Dalam Negeri (KDN) dan perhimpunan yang diadakan tidak mendapat permit polis. Ini ditulis dalam berita, "Perhimpunan haram ada agenda tersirat" (27 Jun 2011).

Menteri Dalam Negeri, Datuk Seri Hishammuddin Tun Hussein berkata perhimpunan haram yang dicadangkan diadakan 9 Julai kononnya berhubung perjalanan pilihan raya sebenarnya mempunyai agenda tersirat yang boleh memudaratkan keadaan di negara ini.:"Ini bermakna semua perhimpunan yang akan diadakan adalah perhimpunan haram dan mereka terpaksa berhadapan dengan tindakan undang-undang," katanya. 


\section{Menjawab Isu-isu Semasa}

UMNO Online juga bertanggungjawab bagi menangkis isu yang dilakukan oleh pembangkang terhadap UMNO dan kerajaan. Namun demikian, penulisan yang terkandung di dalamnya tetap berpegang teguh kepada etika sebagaimana yang digariskan dalam Etika Kewartawanan Malaysia (EKM), iaitu melaporkan kebenaran dan sentiasa menghormati hak orang ramai untuk menerima berita yang benar. Ini dapat dilihat menerusi berita yang diterbitkan pada dalam UMNO Online berkaitan perhimpunan Bersih yang dianggap sebagai gesaan kepada kerajaan untuk membuat lebih awal pilihan raya umum. Presiden UMNO, Dato' Sri Mohd Najib Tun Razak menafikannya dan menjawab tuduhan sebagaimana terkandung dalam berita, “Tiada tekanan tentukan bila pilihan raya umum ke-13" bertarikh 28 Jun 2011.

Datuk Seri Najib Tun Razak berkata rancangan pihak tertentu mahu mengadakan perhimpunan haram kononnya bagi menuntut pilihan raya secara bersih tidak akan memberi tekanan kepadanya untuk memikirkan bila pilihan raya umum bakal diadakan. Perdana Menteri berkata sebenarnya perhimpunan itu bermotif politik dan tuntutan itu boleh diselesaikan tanpa mengheret rakyat untuk menyertai demonstrasi jalanan yang boleh menggugat ketenteraman awam.

Dalam hal ini, Dato' Sri Najib menganggap bahawa tuntutan melalui perhimpunan Bersih adalah bermotif politik dan bukannya bersandarkan agenda yang dinyatakan mereka iaitu mahukan proses pilihan raya di Malaysia yang adil dan telus. Ini kerana, biarpun Bersih menggunakan nama NGO namun perhimpunan ini turut disertai oleh para pemimpin pembangkang termasuklah Dato' Seri Anwar Ibrahim; Presiden PKR, Datin Seri Dr Wan Azizah Wan Ismail; Naib Presiden PAS, Mohamad Sabu; Pengarah Strategi PKR, Rafizi Ramli dan lain-lain lagi. Tuntutan Bersih menganggap pilihan raya tidak adil sedangkan sedangkan dengan pilihan raya 2008, PAS dapat mengekalkan kuasa di Kelantan selama empat penggal dan kemudiannya membentuk pakatan bersama PKR dan DAP yang dapat memenangi Kedah, Selangor dan Pulau Pinang selain banyak kerusi Parlimen yang dimenangi.

\section{KESIMPULAN}

Berdasarkan kajian yang dilakukan, menunjukkan laman UMNO Online menjalankan fungsi dalam menjawab segera tohmahan serta menjelaskan kedudukan sebenar sesuatu perkara khususnya yang dimanipulasikan oleh parti lawan. Penerangan yang dilakukan dalam bentuk wawancara dengan tokoh dan pemimpin berkaliber serta disokong pula paparan gambar dan video mampu menjurus sokongan terhadap kerajaan Barisan Nasional. Sebagai parti politik kejayaan penerangan dan maklumat yang diberi akan diterjemahkan melalui sokongan yang padu kepada UMNO dan tentunya kesetiaan ini akan digambarkan semasa pilihan raya serta pendirian mereka terhadap isu yang ada. Statistik menunjukkan sungguhpun UMNO Online mendapat saingan daripada medium lain seperti radio, televisyen dan kemudiannya Internet yang digunakan oleh laman web pihak lawan dan parti-parti politik lain namun, UMNO Online masih mampu menjalankan fungsi teknologi komunikasi maklumat kepada anggota parti dan masyarakat. Ini dibuktikan sejak kewujudannya, UMNO Online telah melalui dua kali pilihan raya umum iaitu pada pilihan raya umum ke-11 (2004), pada Pilihan Raya Umum ke-12 (2008) dan pada pilihan raya umum ke-13 (2012) menjadi pengantara penting antara UMNO dengan kerajaan Barisan Nasional dengan khalayak.

Melihat dari sudut positif dengan mengharapkan agar UMNO Online dapat ditambah baik sebagai sebuah penerbitan dalam talian yang berpengaruh dan mendatangkan manfaat 
kepada khalayak. Saranan ini dibuat berdasarkan hasil kajian yang telah dilakukan dengan mengambil pertimbangan pelbagai perkara yang terkandung di dalamnya dan juga pemberitaan dalam talian secara umum termasuklah mengaplikasikan sepenuhnya media sosial yang bersifat interaktif dalam penerbitan hari ini. Konsep baru yang mendapat perhatian masyarakat dewasa ini seperti maklumat adalah kuasa, dunia tanpa sempadan, dunia di hujung jari dan globalisasi perlu digunakan sebagai pembuka laluan kepada penerbitan secara dalam talian untuk maju ke hadapan. Keupayaan penerbitan dalam talian yang menjadi pilihan kepada masyarakat tidak boleh dipandang ringan kerana maklumat yang disalurkan dapat sampai dengan pantas kepada khalayak, merentasi masa dan sempadan yang ada. Tidak keterlaluan jika dikatakan berita dalam talian telah menjadi keperluan hidup masyarakat dan ketiadaannya dapat menjadikan seseorang terasa kekurangan dan tidak selesa jika medium tersebut tidak dapat digunakan. Sebagai sebuah laman rasmi UMNO, sememangnya UMNO Online dapat melaksanakan fungsinya, iaitu untuk menyampaikan maklumat berkaitan parti dan dasar kerajaan serta menangkis fitnah yang dibuat oleh pihak pembangkang terhadap UMNO termasuklah para pemimpinnya. Oleh sebab media sosial mampu mempunyai pautan langsung dengan laman web UMNO Online tentunya amat positif sekiranya jumlah ahli UMNO yang ramai dapat dimanifestasikan sebagai jumlah pembaca laman tersebut. Namun begitu masih banyak yang perlu diteroka oleh UMNO Online bagi memastikan fungsinya benar-benar mampu menjadi sebahagian daripada penyampai maklumat kepada khalayak, iaitu tidak rigid kepada ahli UMNO semata-mata.

Walau bagaimanapun, keberkesanan fungsi UMNO Online sebagai gerbang Internet bagi sebuah parti terbesar orang Melayu masih gagal diterjemahkan kepada nilai sebenar berdasarkan angka yang ada. Sebagai sebuah portal yang membawa nama UMNO, UMNO Online sewajarnya memanfaatkan setiap ruang dengan mengaplikasikannya sebagai sumber terdahulu bagi memuatkan berita dan maklumat berkaitan parti berbanding dengan portal yang lain. Sebagaimana slogan UMNO Online, iaitu "Informasi Merentas Masa", tentunya berita yang diterbitkan adalah lebih cepat berbanding media massa lain. Maka tidak wajar sekiranya UMNO Online mengambil bahan berita daripada media lain untuk dijadikan sebagai berita utama. Namun begitu, kajian ini adalah untuk melihat fungsi yang dipertanggungjawabkan apabila berita elektronik UMNO diperkenalkan dan bukan untuk mengukur setakat mana keberkesanannya kepada khalayak. Apa-apa pun, perubahan semasa dan peningkatan pengetahuan dan teknologi perlulah sealiran dengan penglibatan ahli-ahlinya dalam memberikan sokongan kepada media baru yang diaplikasikan UMNO. Media massa mampu berperanan sebagai agen pemujukan dan sokongan politik selain peranannya sebagai pembentuk agenda. Oleh itu, peranan ini tentulah tidak mustahil untuk turut diaplikasikan agar penggunaan UMNO Online itu sendiri dapat digunakan semaksimumnya. Jika tidak, UMNO Online hanya akan berfungsi sekadar sebuah laman web yang hanya memberikan penerangan berkaitan parti tetapi gagal dalam persaingan berita berbentuk portal.

\section{RUJUKAN}

Ab Jalil Aboo Backer. (2010). Penerbitan akhbar Internet di Malaysia: Kajian ke atas Utusan Malaysia (Disertasi Sarjana tidak diterbitkan). Jabatan Pengajian Media, Fakulti Sasteran dan Sains Sosial, Universiti Malaya, Kuala Lumpur. 
Ab Rauf Yusoh. (2011, 25 September). Wawancara.

Abbott, J. P. (2004). The Internet, reformasi and democratisation in Malaysia. In E. T. Gomez (ed.), The state of Malaysia: Ethnicity, equity and reform, (hlm. 79-104). London/New York: Routledge.

Abdul Nassir Said. (2003). Penerbitan elektronik dan penerbitan konvensional: Perbandingan antara akhbar dalam talian dengan akhbar cetak. (Disertasi Sarjana tidak diterbitkan). Jabatan Pengajian Media, Fakulti Sasteran dan Sains Sosial, Universiti Malaya, Kuala Lumpur.

Adnan Hussein dan Kamaliah Hj Siarap. (2000). Penggunaan teknologi komunikasi-informasi di kalangan ahli akademik di Malaysia. Jurnal Komunikasi, 16, 119-130:

Ahmad Kamal Zailani. (2011, 2 dan 4 Ogos). Wawancara.

Ahmad Zaky Daud. (2002). Peranan akhbar dalam kempen Piliharaya di Malaysia: Satu tinjauan terhadap Harakah dalam Pilihanraya Umum Ke-10 (1999). (Disertasi Sarjana tidak diterbitkan. Jabatan Siasah Syar'iyyah, Akademi Pengajian Islam Universiti Malaya, Kuala Lumpur.

Che Yazid Che Seman. (2001). Pelanggaran etika kewartawanan di Malaysia 1994 : Kajian kes di liputan kepimpinan GAPENA dan politik Abdul Rahim Thamby Chik. (Disertasi Sarjana tidak diterbitkan). Jabatan Pengajian Media, Fakulti Sasteran dan Sains Sosial, Universiti Malaya, Kuala Lumpur.

Dozier, D. \& Rice, R. E. (1984). Rival theories of electronic newsreading. In R. E. Rice (Ed.), The new media: Communication, research and technology (hlm. 103-127). Beverly Hills, CA: Sage.

HarakahDaily. (2012) About HarakahDaily Online. Akses dari http://www.harakahdaily. my/about.

Hsieh, H. F., \& Shannon, S. E. (2005). Three approaches to qualitative content analysis. Qualitative Health Research, 15 (9), 1277-1288.

Kuan Yee Cheng. (1999). Penerbitan elektronik: satu tinjauan dalam penerbitan akhbar The Star Online. (Disertasi Sarjana tidak diterbitkan). Jabatan Pengajian Media, Fakulti Sasteran dan Sains Sosial, Universiti Malaya, Kuala Lumpur.

Maizatul Nazlina Mohd Zawawi. (2002). Kajian tentang akhbar-akhbar dalam talian tumpuan terhadap NSTP $(M)$ Bhd, The Star Publications (M) Bhd dan Harakah. (Disertasi Sarjana tidak diterbitkan). Jabatan Pengajian Media, Fakulti Sasteran dan Sains Sosial, Universiti Malaya, Kuala Lumpur

Malaysiakini. (2012). About Us. Malaysiakini.com. Akses dari http://mkini.blogspot.com/p/ about-us.html.

McQuail, D. (1987). Mass communication theory: An introduction.(2nd Edition). London: Sage Publications.

Mohd Yusof Kasim dan Azlan Ahmad. (2002). Politik baru dalam pilihan raya umum. Bangi: Penerbit Universiti Kebangsaan Malaysia.

Ng Jiun Yen. (2008). Pengaplikasian teori kegunaan dan kepuasan oleh Penerbit Universiti: suatu kajian terhadap penerbitan ilmiah elektronik. (Disertasi Sarjana tidak diterbitkan). Jabatan Pengajian Media, Fakulti Sasteran dan Sains Sosial, Universiti Malaya, Kuala Lumpur.

Nik Yahya Ab Rahman. (2012). Barisan Nasional ke arah mencapai kemenangan PRU-13. Batu Caves: Thinker's Library Sdn. Bhd.

Nolan Jeffrey Abdul Hai. (2004). Kajian akhbar dalam talian : kajian rekabentuk The STAR Online. (Disertasi Sarjana tidak diterbitkan). Jabatan Pengajian Media, Fakulti Sasteran dan Sains Sosial, Universiti Malaya, Kuala Lumpur. 
Penyata Tahunan UMNO 1999-2000. (2000) Kuala Lumpur: Ibu Pejabat UMNO.

Penyata Tahunan UMNO 2003-2004. (2004) Kuala Lumpur: Ibu Pejabat UMNO.

Penyata Tahunan UMNO 2004-2005. (2005) Kuala Lumpur: Ibu Pejabat UMNO.

Rice, R. E. (2002). Primary issues in internet use: access, civic and community involvement,and social interaction and expression. In Lievrouw, L. A. \& Livingston, S. (Eds.) Handbook of New Media, (hlm. 105-130). London, SAGE Publications Ltd.

Mohd Sani, Mohd Azizuddin \& Zengeni, Knocks Tapiwa (2010) Democratisation in Malaysia: The impact of social media in the 2008 general election. Dlm. Asian Studies Association of Australia (ASAA) 18th Biennial Conference 2010, 5 - 8 July, The University of Adelaide, Australia. 